\title{
Punctal eversion with silicone plug resulting in ocular surface trauma
}

\author{
Brad P Barnett (10, ${ }^{1}$ Esen K Akpek, ${ }^{2}$ Albert S Jun ${ }^{2}$
}

${ }^{1}$ Ophthalmology, Duke Medicine, Durham, North Carolina, USA ${ }^{2}$ Ophthalmology, Johns Hopkins Medicine Wilmer Eye Institute, Baltimore, Maryland, USA

\section{Correspondence to}

Dr Brad P Barnett;

bradley.barnett@duke.edu

Accepted 14 May 2020

\section{DESCRIPTION}

A woman in her 70s with a history of chronic mixed mechanism ocular surface disease presented with an epithelial defect in her left eye. She was status post lower punctal cautery and was currently on Xiidra (lifitegrast ophthalmic solution, 5\%) two times per day. On presentation, she endorsed foreign body sensation with $4 / 10$ pain in her left eye. She was found to have a circular epithelial defect $1.5 \mathrm{~mm}$ in diameter (figure 1). Additionally, she had a vertically oriented, roughly linear area of conjunctival hyperaemia and chemosis nasally (figure 1). She endorsed her symptoms began to worsen approximately 1 month ago when she had undergone placement of an UltraPlug Silicone Plug (Angiotech, Vancouver, BC, Canada) in her left upper punctum.

In the setting of the pouting configuration of the upper punctum, the silicone plug, though well seated, caused direct contact of the plug to the ocular surface. With removal of the plug, the corneal epithelial defect and conjunctival inflammation resolved. Previous case reports describe granuloma formation ${ }^{1}$ and canaliculitis ${ }^{2}$ resulting from punctal plugs. Moreover, it is known that silicone punctal plugs can traumatise the ocular surface in the setting of partial extrusion of the plug, especially in the context of rigid plugs with thick collarettes. ${ }^{3}$ This case highlights the ocular surface trauma that may result when the plug's collarette is oriented

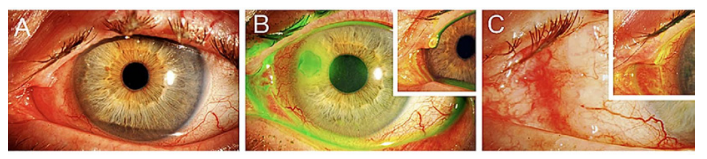

Figure 1 (A) Left eye slit lamp photograph demonstrating primarily a nasal conjunctival injection with prominent UltraPlug Silicone Plug (Angiotech, Vancouver, BC, Canada) well seated in a pouting punctum. (B) Slit lamp photograph of the same eye with fluorescein staining demonstrating an epithelial defect, with inset photograph showing punctal plug abrading cornea in the same position when patient adducts the eye. (C) Slit lamp photograph of the same eye demonstrating a linear conjunctival hyperaemia, with inset photograph demonstrating apposition of the plug to conjunctiva with vertical deviation of the eye.

\section{Learning points}

- Use of a punctal plug in the setting of punctal eversion may lead to ocular trauma.

- After punctal silicone plug placement, it is critical to observe final plug position.

- Silicone plugs with larger collarette or increased rigidity can lead to ocular surface damage.

towards the ocular surface. It further highlights the importance of evaluating the punctal position prior to and after plug placement, to ensure that no direct apposition of the plug to the ocular surface occurs. As evidenced by this case, significant ocular surface trauma can occur with a silicone plugged pouting punctum. It is likely that in all instances of punctal plugs with an external collarette, some degree of ocular surface trauma is incurred. This case highlights the importance of considering punctal configuration and final plug position when performing punctal occlusion.

Contributors BPB, EKA and ASJ performed substantial contributions to the conception or design of the work, or the acquisition, analysis or interpretation of data; drafting the work or revising it critically for important intellectual content; final approval of the version published; agreement to be accountable for all aspects of the work in ensuring that questions related to the accuracy or integrity of any part of the work are appropriately investigated and resolved.

Funding The authors have not declared a specific grant for this research from any funding agency in the public, commercial or not-for-profit sectors.

Competing interests None declared.

Patient consent for publication Obtained.

Provenance and peer review Not commissioned; externally peer reviewed.

ORCID iD

Brad P Barnett http://orcid.org/0000-0002-8301-404X

\section{REFERENCES}

1 Kim BM, Osmanovic SS, Edward DP. Pyogenic granulomas after silicone punctal plugs: a clinical and histopathologic study. Am J Ophthalmol 2005;139:678-84.

2 Rumelt S, Remulla H, Rubin PA. Silicone punctal plug migration resulting in dacryocystitis and canaliculitis. Cornea 1997;16:377-9.

3 Best A-L, Labetoulle M, Legrand M, et al. Punctal and canalicular plugs: indications, efficacy and safety. J Fr Ophtalmol 2019;42:e95-104. 
Images in...

Copyright 2020 BMJ Publishing Group. All rights reserved. For permission to reuse any of this content visit https://www.bmj.com/company/products-services/rights-and-licensing/permissions/

BMJ Case Report Fellows may re-use this article for personal use and teaching without any further permission.

Become a Fellow of BMJ Case Reports today and you can:

- Submit as many cases as you like

Enjoy fast sympathetic peer review and rapid publication of accepted articles

Access all the published articles

Re-use any of the published material for personal use and teaching without further permission

Customer Service

If you have any further queries about your subscription, please contact our customer services team on +44 (0) 2071111105 or via email at support@bmj.com.

Visit casereports.bmj.com for more articles like this and to become a Fellow 